ARTICLE

\title{
Preliminary Estimation of Long-lived Activation Products in the Reactor Structures of SMART
}

\author{
Kyo-Youn Kim*, Ha-Young Kim, Gyu-Hong Rho, Dong-Seong Sohn \\ Korea Atomic Energy Research Institute, 1045 Daedoek-daero, Yuseong-gu, Daejeon, 305-353, Korea
}

\begin{abstract}
The structural material of an integral reactor SMART is irradiated by neutrons released during fission reactions of a reactor core. The fission process is not a major contributor to a worker's dose at the power plants because the fission process is occurring in the reactor core inside a reactor vessel. The reactor vessel is located within the reactor cavity inside the containment, and workers are not normally allowed to be around the reactor vessel during operation. The total neutron flux in the reactor vessel of SMART was calculated using the GEOSHIELD code. The radioactivity due to activation products in a flow mixing header assembly and in a reactor pressure vessel of the integral reactor was estimated using the ORIGEN2.2 code preliminarily. It was assumed that the materials have been irradiated for 60 years at full power and the irradiation was under constant neutron fluxes. The radioactivity due to activation products in the structural material is used to estimate the exposure level of radiation workers around the reactor vessel.
\end{abstract}

KEYWORDS: neutron activation, GEOSHIELD, DORT, ORIGEN2.2,

\section{Introduction}

The radioactivity due to activation product is, in general, evaluated in order to provide information on radiological environment during maintenance and decommissioning of a nuclear power plant. Especially, the evaluation of activation products is a guidance to determine decommissioning technologies, to estimate radiation dose of worker and public, to select the decontamination technologies and determine requirements for disposal and transportation of radioactive material.

SMART, System-integrated Modular Advanced Reactor, has been developed by Korea Atomic Energy Research Institute(KAERI) by combining innovative safety features and its own indigenous technologies with proven LWR technologies. The SMART reactor has substantially enhanced its safety with an integral layout of its major components, such as the reactor core, steam generator, coolant pump, and pressurizer which are integrated within a single pressure vessel. The SMART reactor can serve the dual purposes of seawater desalination and electricity generation. Thus SMART can supply water and energy simultaneously to large industrial areas or isolated areas such as islands. KAERI is developing an updated SMART reactor which can generate a thermal power of $330 \mathrm{MW}$.

During the fission process of the SMART reactor, high energy gamma rays and high energy neutrons are released. Since neutrons and gamma rays can travel long distances in structures of a nuclear reactor, very high radiation levels are present in the vicinity of the reactor pressure vessel during power operation. The structural material of the SMART reactor is irradiated by neutrons released during fission reactions of a reactor core. The fission process is not a major contributor to a worker's dose at the nuclear power reactors

*Corresponding Author, E-mail:sky@kaeri.re.kr

(C) Atomic Energy Society of Japan because the fission process is occurring in the nuclear fuel of reactor core inside a reactor vessel. The reactor pressure vessel is located within the reactor cavity inside the containment, and workers are not normally allowed to be nearby the reactor vessel during operation.

Although the gamma rays contribute to the radiation levels near the reactor vessel, they are not a significant source of exposure because workers are not normally present in the vessel area during operation. But the fuel is removed from the reactor vessel during refueling. The workers could be exposed to the radiation from the activation products in the reactor vessel.

The thermal, epithermal and fast neutron fluxes in the reactor vessel of the SMART reactor were calculated using the GEOSHIELD code ${ }^{1)}$. The radioactivity due to activation products in the structural material of the integral reactor was estimated using the ORIGEN2.2 $\operatorname{code}^{2)}$. The ORIGEN2.2 code calculates time-dependent concentrations and radioactive source terms for a large number of isotopes, which are simultaneously generated or depleted through neutronic transmutation, fission, radioactive decay, input feed rates, and physical or chemical removal rates. It was assumed that the materials have been irradiated for 60 years at full power and that the irradiation was under constant neutron fluxes. The radioactivity due to activation products in the structural material is used to estimate the exposure level of radiation workers around the reactor vessel.

\section{Transport Calculation}

The neutron flux distribution in the SMART reactor, which will be used in a calculation of radioactivities of activation product in the structures of the SMART reactor, was estimated using the GEOSHIELD code. The GEOSHIELD code includes an original geometry construction by using various structures with a given composition and source; a mesh generation to be used in 
the DORT code $^{3)}$ calculation; a composition and source assignment to each mesh; the DORT code input generation; the DORT code output processing; and a graphical visualization. The fundamental idea of the mesh generation includes three steps. The first one is to construct the original core geometry with various combinations of structures consisting of basic cells including polygon, circle, ellipse and pie geometries.

The quarter symmetry of the SMART reactor is shown in Fig. 1. As shown in Fig. 1 the flow mixing header assembly locates between a reactor core barrel and a reactor pressure vessel to assist a proper flow of coolant in a downcomer.

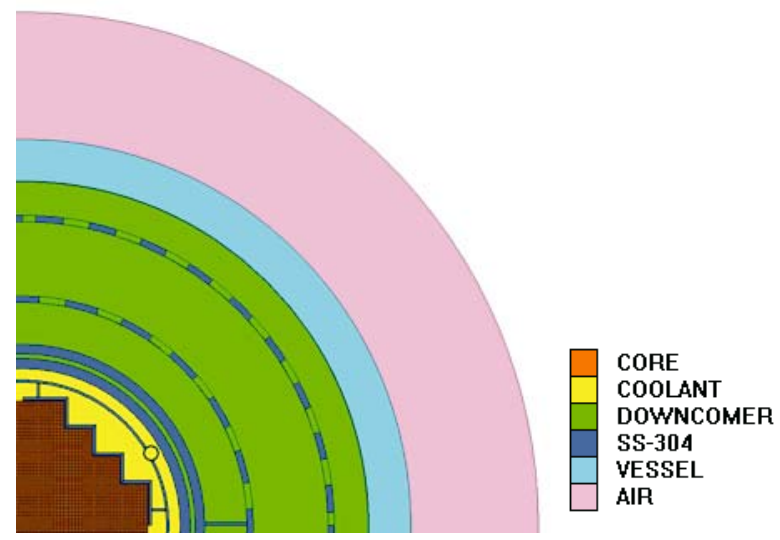

Fig. 1 The radial structure of SMART for the GEOSHIELD calculation.

The R- $\Theta$ models include most of the reactor components with the consideration of an azimuthally homogeneous core configuration. The geometrical model extends radially from the core centerline to the outer surface of the reactor vessel. 194 radial and 180 azimuthal meshes were used in the R- $\Theta$ model as shown in Fig. 1. A $\mathrm{P}_{5}$ scattering expansion and a $\mathrm{S}_{8}$ angular quadrature set were used for the DORT code calculation. For the energy spectrum, the Watt fission spectrum normalized to the thermal power density was used. BUGLE-96 library ${ }^{4)}$ was used for the 67 group coupled neutron and gamma-ray cross-section data for the DORT code calculation, which consists of 47 neutron and 20 gamma energy groups. Overall a 30\% uncertainty was applied to the total neutron flux calculated by the GEOSHIELD code so that an uncertainty due to a dimensional tolerance, representation of a source distribution and cross-section can be supplemented.

The total neutron flux distribution in the SMART reactor using the GEOSHIELD code is shown in Fig. 2. The maximum total neutron flux at the flow mixing header assembly and the reactor pressure vessel are $1.0 \times 10^{12}$ $\mathrm{n} / \mathrm{cm}^{2} \cdot \mathrm{sec}$ and $2.0 \times 10^{11} \mathrm{n} / \mathrm{cm}^{2} \cdot \mathrm{sec}$, respectively.

\section{Activation Product}

Activation products are a common radioactive source of structural materials present inside a nuclear reactor vessel to be concerned about radiation exposure of radiation worker.
The activation products are produced from bombarding target materials with various radiations such as neutrons, protons, deuterons and from various nuclear reactions.

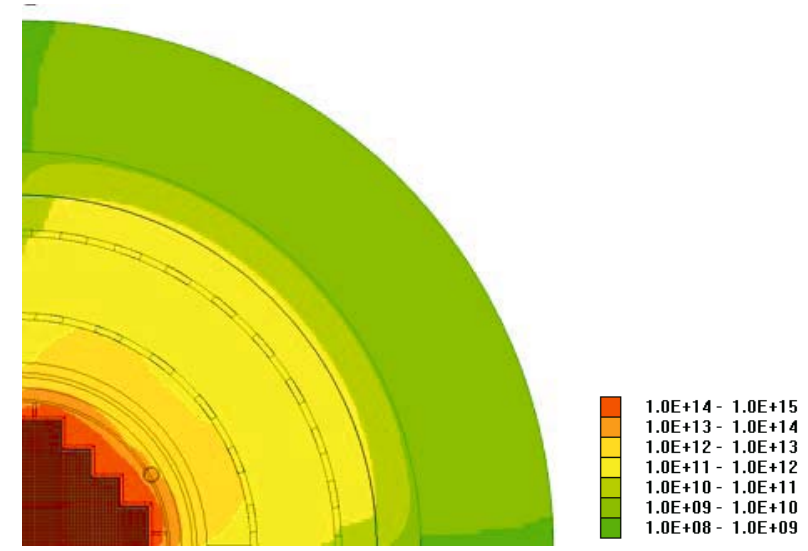

Fig. 2 Total neutron flux distribution for R- $\theta$ model of the SMART reactor

The material of the flow mixing head assembly is a stainless steel type SS304 and that of the reactor pressure vessel is ASME SA508. The averaged values of chemical composition of materials are shown in Table 1. The weight of composition atoms in each material was calculated using the values shown in Table 1.

Given the material compositions in unit of gram-atom, the radioactivities for each structural component were estimated with the ORIGEN2.2 code. The ORIGEN2.2 code calculates time-dependent concentrations and radioactive source terms for a large number of isotopes, which are simultaneously generated or depleted through neutronic transmutation, fission, and radioactive decay.

Table 1 Chemical compositions of flow mixing head assembly and reactor pressure vessel

\begin{tabular}{ccc}
\hline \multirow{2}{*}{ Element } & \multicolumn{2}{c}{ Chemical Composition (\%) } \\
\cline { 2 - 3 } & Flow Mixing Header Assembly & Reactor Pressure Vessel \\
\hline $\mathrm{C}$ & 0.08 & 0.25 \\
$\mathrm{Si}$ & 0.75 & 0.27 \\
$\mathrm{P}$ & 0.04 & 0.02 \\
$\mathrm{~S}$ & 0.03 & 0.02 \\
$\mathrm{~V}$ & - & 0.05 \\
$\mathrm{Cr}$ & 19.00 & 0.25 \\
$\mathrm{Mn}$ & 2.00 & 1.35 \\
$\mathrm{Fe}$ & 68.60 & 96.56 \\
$\mathrm{Ni}$ & 9.50 & 0.70 \\
$\mathrm{Mo}$ & - & 0.53 \\
\hline
\end{tabular}

The analysis assumed that:

- the materials have been irradiated for 60 years at full power.

- the irradiation was under constant neutron fluxes.

- a cobalt impurity of 0.38 weight percent ${ }^{5)}$ was considered to incorporated in the chemical composition shown in Table 1.

Although the ORIGEN2.2 code calculations include actinides and fission products, which are from uranium 
impurities in the material compositions, their contributions to radioactivity are much smaller than those of light elements. Therefore, the contribution from actinides and fission products are not considered in this analysis and discussion on radioactivity.

In general, the short lived nuclides are dominant during the reactor operation, but the long lived nuclides are dominant during the reactor cooling time after reactor shutdown. Thus the long lived nuclides are more important than the short lived nuclides in terms of radiation protection.

\section{Results and Discussion}

The radioactivities in the structural material of the SMART reactor due to the activation reaction were estimated using the total neutron flux distribution resulted from the GEOSHIELD code calculation and the ORIGEN2.2 code calculation.

\section{Flow Mixing Header Assembly}

During the reactor operation, the most important radionuclides (the gamma emitters) in the flow mixing header assembly of SS-304 including a cobalt impurity are produced by neutron reaction such as ${ }^{59} \mathrm{Co}(\mathrm{n}, \gamma){ }^{60} \mathrm{Co}$ (half life $=5.3$ y), ${ }^{50} \mathrm{Cr}(\mathrm{n}, \gamma){ }^{51} \mathrm{Cr}$ (half life $=27.7 \mathrm{~d}$ ), ${ }^{64} \mathrm{Ni}(\mathrm{n}, \gamma){ }^{65} \mathrm{Ni}$ (half life $=2.52 \mathrm{~h}$ ), and ${ }^{62} \mathrm{Ni}(\mathrm{n}, \gamma)^{63} \mathrm{Ni}$ (half life $=100 \mathrm{y}$ ).

Figure 3 shows specific radioactivity due to dominant nuclides during reactor operation of 60 years at the flow mixing header assembly. It is shown that the specific activity resulted from activation reaction of ${ }^{59} \mathrm{Co}(\mathrm{n}, \gamma){ }^{60} \mathrm{Co}$ is the most dominant value closed to total activity of $7.8 \times 10^{11} \mathrm{~Bq} / \mathrm{cm}^{3}$ during the reactor operation.

During the reactor cooling after 60 years operation of the SMART reactor, the most important radionuclides in the flow mixing header assembly are produced by neutron reaction such as ${ }^{59} \mathrm{Co}(\mathrm{n}, \gamma){ }^{60} \mathrm{Co}$ (half life $\left.=5.3 \mathrm{y}\right),{ }^{62} \mathrm{Ni}(\mathrm{n}, \gamma){ }^{63} \mathrm{Ni}$ (half life=100.1 y), ${ }^{54} \mathrm{Fe}(\mathrm{n}, \gamma){ }^{55} \mathrm{Fe}$ (half life=2.7 y).

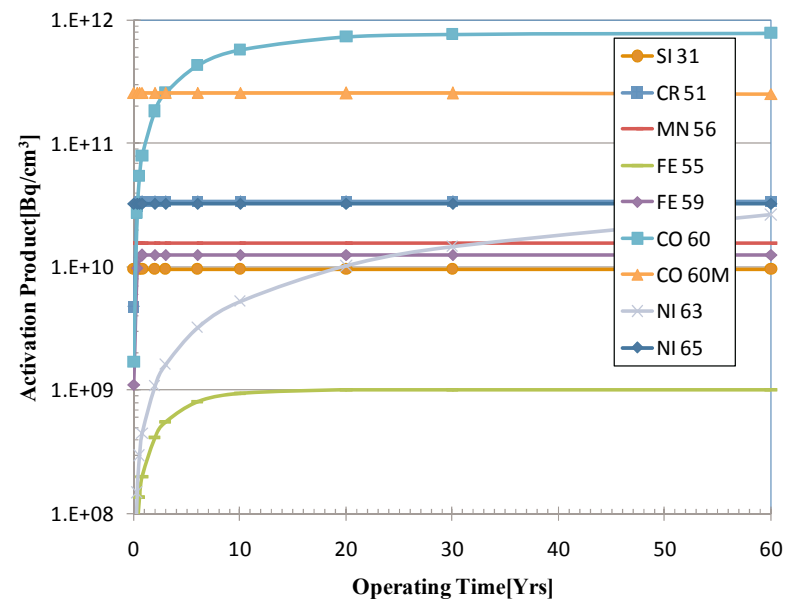

Fig. 3 Specific activity during reactor operation of 60 years at the flow mixing head assembly

Figure 4 shows specific radioactivity due to dominant nuclides during reactor cooling after reactor operation of 60 years at the flow mixing head assembly. It is shown that the specific activity resulted from activation reaction of ${ }^{62} \mathrm{Ni}(\mathrm{n}, \gamma){ }^{63} \mathrm{Ni}$ is the most dominant value closed to total activity of $2.6 \times 10^{10} \mathrm{~Bq} / \mathrm{cm}^{3}$ during the reactor cooling.



Fig. 4 Specific activity during reactor cooling after reactor operation of 60 years at the flow mixing header assembly

Although ${ }^{31} \mathrm{Si}$ and ${ }^{51} \mathrm{Cr}$ are initially dominant in terms of activity, their activities are decreased in a short time because of very short half lives. The specific activity of ${ }^{60} \mathrm{Co}$, $7.8 \times 10^{11} \mathrm{~Bq} / \mathrm{cm}^{3}$, is the most dominant nuclide at the time of reactor shutdown, but that is decreased to $7.8 \times 10^{11} \mathrm{~Bq} / \mathrm{cm}^{3}$ at the time of 30 years cooling because of 5.27 years half life. But the specific activity of ${ }^{63} \mathrm{Ni}, 2.1 \times 10^{10} \mathrm{~Bq} / \mathrm{cm}^{3}$, is the most dominant at 30 years after shutdown cooling. ${ }^{60} \mathrm{Co}$ and ${ }^{59} \mathrm{Ni}$ will remain high. Thus, ${ }^{63} \mathrm{Ni},{ }^{60} \mathrm{Co},{ }^{55} \mathrm{Fe}$, and ${ }^{10} \mathrm{Be}$ are the most important radionuclides in viewpoint of radiation shielding design.

\section{Reactor Pressure Vessel}

During the reactor operation, the most important radionuclides (the gamma emitters) in the reactor pressure vessel of SA-508 including a cobalt impurity are produced by neutron reaction such $\mathrm{as}^{50} \mathrm{Cr}(\mathrm{n}, \gamma){ }^{51} \mathrm{Cr}($ half life $=27 \mathrm{~d})$, ${ }^{59} \mathrm{Co}(\mathrm{n}, \gamma){ }^{60} \mathrm{Co}$ (half life $\left.=5.3 \mathrm{y}\right),{ }^{62} \mathrm{Ni}(\mathrm{n}, \gamma){ }^{63} \mathrm{Ni}$ (half life $=100.1$ y), ${ }^{64} \mathrm{Ni}(\mathrm{n}, \gamma){ }^{65} \mathrm{Ni}$ (half life $\left.=2.5 \mathrm{~h}\right),{ }^{62} \mathrm{Ni}(\mathrm{n}, \gamma){ }^{63} \mathrm{Ni}$ (half life $=100$ $\mathrm{y}$ ), and ${ }^{98} \mathrm{Mo}(\mathrm{n}, \gamma){ }^{99} \mathrm{Mo}$ (half life $=66 \mathrm{~h}$ ).

Figure 5 shows specific radioactivity due to dominant nuclides during reactor operation of 60 years at the reactor pressure vessel. It is shown that the specific activity resulted from activation reaction of ${ }^{50} \mathrm{Cr}(\mathrm{n}, \gamma){ }^{51} \mathrm{Cr}$ is the most dominant value closed to total activity $5.2 \times 10^{11} \mathrm{~Bq} / \mathrm{cm}^{3}$ during the reactor operation.

During the reactor cooling after 60 years operation of the SMART reactor, the most important radionuclides in the flow mixing header assembly are produced by neutron reaction such as ${ }^{59} \mathrm{Co}(\mathrm{n}, \gamma){ }^{60} \mathrm{Co}$ (half life $\left.=5.3 \mathrm{y}\right),{ }^{62} \mathrm{Ni}(\mathrm{n}, \gamma){ }^{63} \mathrm{Ni}$ (half life $=100.1 \mathrm{y}$ ), ${ }^{58} \mathrm{Ni}(\mathrm{n}, \gamma){ }^{59} \mathrm{Ni}$ (half life $=0.076 \mathrm{My}$ ), ${ }^{92} \mathrm{Mo}(\mathrm{n}, \gamma){ }^{93} \mathrm{Mo}$ (half life $=4.0 \mathrm{y}$ ). 


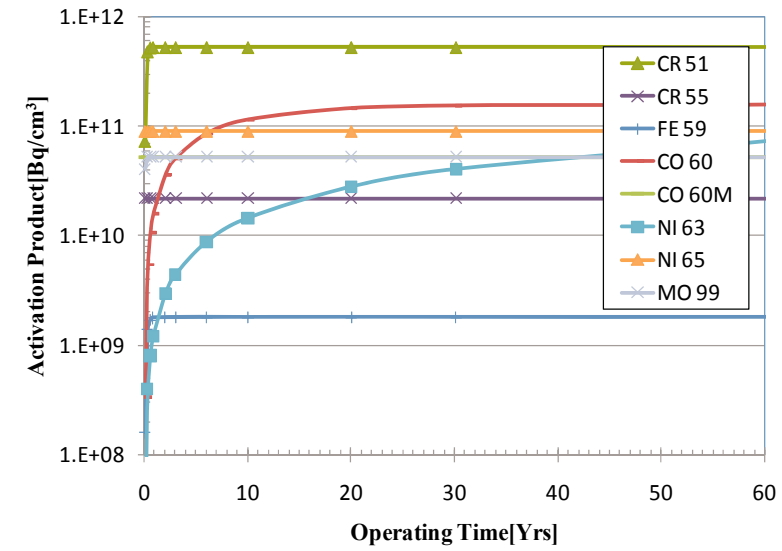

Fig. 5 Specific activity during reactor operation of 60 years at the reactor pressure vessel

Figure 6 shows specific radioactivity due to dominant nuclides during reactor cooling after reactor operation of 60 years at the reactor pressure vessel. It is shown that the specific activity resulted from activation reaction of ${ }^{62} \mathrm{Ni}(\mathrm{n}, \gamma){ }^{63} \mathrm{Ni}$ is the most dominant value closed to total activity between $7.2 \times 10^{10} \mathrm{~Bq} / \mathrm{cm}^{3}$ and $5.7 \times 10^{10} \mathrm{~Bq} / \mathrm{cm}^{3}$ during the reactor cooling.

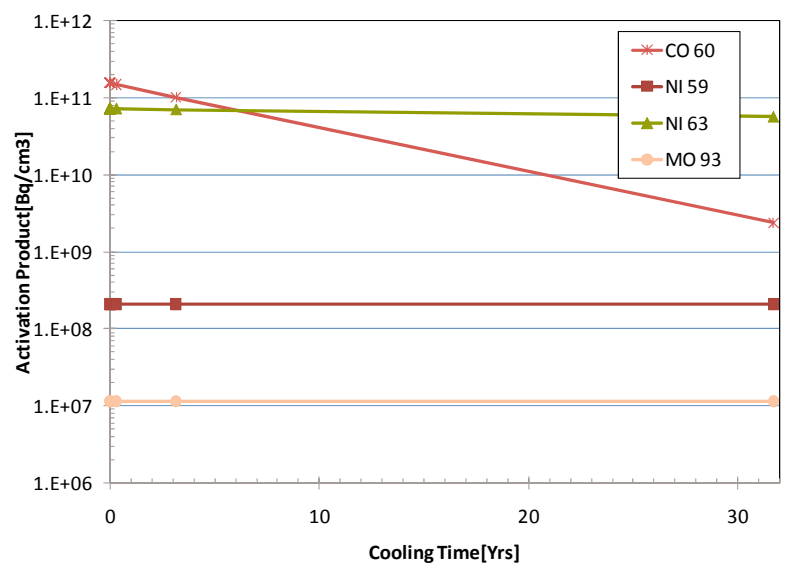

Fig. 6 Specific activity during reactor cooling after reactor operation of 60 years at the reactor pressure vessel

Although ${ }^{51} \mathrm{Cr}$ and ${ }^{55} \mathrm{Cr}$ are initially dominant in terms of activity, their activities are decreased in a short time because of very short half lives. The specific activity of ${ }^{60} \mathrm{Co}$, $1.6 \times 10^{11} \mathrm{~Bq} / \mathrm{cm}^{3}$, is the most dominant nuclide at the time of reactor shutdown, but that is decreased to $2.4 \times 10^{9} \mathrm{~Bq} / \mathrm{cm}^{3}$ at the time of 30 years cooling because of 5.27 years half life. But the specific activity of ${ }^{63} \mathrm{Ni}, 5.7 \times 10^{10} \mathrm{~Bq} / \mathrm{cm}^{3}$, contributes dominantly to total specific activity at 30 years after shutdown cooling. The specific activities of ${ }^{60} \mathrm{Co}$ and ${ }^{59} \mathrm{Ni}$ will remain high. Thus, ${ }^{63} \mathrm{Ni},{ }^{60} \mathrm{Co},{ }^{59} \mathrm{Ni}$ and ${ }^{93} \mathrm{Mo}$ are the most important radionuclides in viewpoint of radiation shielding design.

\section{Conclusion}

The structural material of an integral reactor SMART is irradiated by neutrons released during fission reactions of a reactor core. The total neutron flux in the reactor pressure vessel of the SMART reactor was calculated using the GEOSHIELD code. The radioactivity due to activation products in a flow mixing header assembly and in a reactor pressure vessel of the integral reactor was estimated using the ORIGEN2.2 code preliminarily.

Since the neutron flux is decreased as an increasing of radial distance, the radioactivity of activation product also decreases from core to the reactor pressure vessel in general. In the flow mixing header assembly, it was evaluated that most of total activity comes from the nuclides of ${ }^{63} \mathrm{Ni}$ and ${ }^{60} \mathrm{Co}$. The activity of ${ }^{63} \mathrm{Ni}$ is dominant of the whole activity about 30 years from shutdown. The maximum total specific activity of the flow mixing header assembly is between $1.1 \times 10^{12} \mathrm{~Bq} / \mathrm{cm}^{3}$ and $3.3 \times 10^{10} \mathrm{~Bq} / \mathrm{cm}^{3}$ during the reactor cooling.

In the reactor pressure vessel, it was evaluated that most of total activity comes from the nuclides of ${ }^{63} \mathrm{Ni}$ and ${ }^{60} \mathrm{Co}$. The activity of ${ }^{63} \mathrm{Ni}$ is dominant of the whole activity about 30 years from shutdown. The maximum total specific activity of the reactor pressure vessel is between $1.0 \times 10^{12}$ $\mathrm{Bq} / \mathrm{cm}^{3}$ and $6.0 \times 10^{10} \mathrm{~Bq} / \mathrm{cm}^{3}$ during the reactor cooling.

The specific activities of the structural material will be used as source terms of radiation shielding design to protect workers during the maintenance duration and during radioactive waste disposal of reactor structures.

\section{Acknowledgment}

This work was performed under the auspices of Korea Ministry of Education, Science and Technology as a long term R\&D project.

\section{References}

1) K. S. Kim, K. Y. KIM, H. Y. KIM, C. H. Lee and S. Q. Zee, "Development of the GEOSHIELD Program for the Automatic Particle Transport Calculation Using DORT," Proc. 2006 Autumn Meeting of Korean Association for Radiation Protection, Gyoengjoo, Korea, Nov. 23-24, 2006, 94 (2006), [in Korean].

2) Allen G. Croff, A user's manual for ORIGEN2.2 computer code, ORNL/TM-7175, Oak Ridge National Laboratory, (1980).

3) W. A. Rhoades and R. L. Childs, TORT-DORT Two- and Three-Dimensional Discrete Ordinates Transport Code Version 2.12.14, CCC-543, Oak Ridge National Laboratory, (1995).

4) J. E. White, et. Al., BUGLE-96: Coupled 47 Neutron-20 Gamma-Ray Group Cross Section Library Derived from ENDF/B-VI for LWR Shielding and Vessel Dosimetry Application," DLC-185, Oak Ridge National Laboratory, (1996)

5) A. S. Zhilkin, O. V. Starkov and E. V. Shestopalov, Cobalt and other impurities in reactor Steels, Atomnaya Énergiya, 52[ 4], 261(1982). 